Article

\title{
The Design of ZnO Nanorod Arrays Coated with MnOx for High Electrochemical Stability of a Pseudocapacitor Electrode
}

\author{
Hsiang-Chun Chen ${ }^{1}$, Yang-Ru Lyu ${ }^{1}$, Alex Fang ${ }^{2}$, Gang-Juan Lee ${ }^{3}$, Lakshmanan Karuppasamy ${ }^{3}$, \\ Jerry J. Wu ${ }^{3}$, Chung-Kwei Lin ${ }^{4,5, * \mathbb{D}}$, Sambandam Anandan ${ }^{6}$ and Chin-Yi Chen ${ }^{1,2,5, * \mathbb{D}}$ \\ 1 Department of Materials Science and Engineering, Feng Chia University, Taichung 407, Taiwan; \\ judy930410@hotmail.com (H.-C.C.); yrlyu.mse96g@g2.nctu.edu.tw (Y.-R.L.) \\ 2 Department of Engineering Technology and Industrial Distribution, Texas A\&M University, \\ College Station, TX 77843, USA; gpafang@tamu.edu \\ 3 Department of Environmental Engineering and Science, Feng Chia University, Taichung 407, Taiwan; \\ leeganjiuan@gmail.com (G.-J.L.); lksamylaksh@gmail.com (L.K.); jjwu@mail.fcu.edu.tw (J.J.W.) \\ 4 School of Dental Technology, College of Oral Medicine, Taipei Medical University, Taipei 110, Taiwan \\ 5 Research Center of Digital Oral Science and Technology, College of Oral Medicine, Taipei Medical University, \\ Taipei 110, Taiwan \\ 6 Nanomaterials and Solar Energy Conversion Laboratory, Department of Chemistry, \\ National Institute of Technology, Trichy 620015, India; sanand99@yahoo.com \\ * Correspondence: chungkwei@tmu.edu.tw (C.-K.L.); chencyi@fcu.edu.tw (C.-Y.C.)
}

Received: 12 February 2020; Accepted: 3 March 2020; Published: 6 March 2020

check for updates

\begin{abstract}
Tremendous efforts have been made on the development of unique electrochemical capacitors or pseudocapacitors due to the overgrowing electrical energy demand. Here, the authors report a new and simple strategy for fabricating hybrid $\mathrm{MnOx}$-coated $\mathrm{ZnO}$ nanorod arrays. First, the vertically aligned $\mathrm{ZnO}$ nanorods were prepared by chemical bath deposition (CBD) as a template providing a large surface area for active material deposition. The manganese oxide was subsequently coated onto the surface of the $\mathrm{ZnO}$ nanorods to form a hybrid MnOx-coated $\mathrm{ZnO}$ nanostructure by anodic deposition in a manganese acetate (MnA)-containing aqueous solution. The hybrid structure of $\mathrm{MnOx}$-coated $\mathrm{ZnO}$ nanorod arrays exhibits a large surface area and high conductivity, essential for enhancing the faradaic processes across the interface and improving redox reactions at active $\mathrm{MnOx}$ sites. A certain concentration of the deposition solution was selected for the $\mathrm{MnOx}$ coating, which was studied as a function of deposition time. Cyclic voltammetry (CV) curves showed that the specific capacitance (SC) of the MnOx-coated $\mathrm{ZnO}$ nanostructure was $222 \mathrm{~F} / \mathrm{g}$ for the deposition times at $10 \mathrm{~s}$ when the concentration of MnA solution was $0.25 \mathrm{M}$. The unique hybrid nanostructures also exhibit excellent cycling stability with $>97.5 \%$ capacitance retention after $1200 \mathrm{CV}$ cycles. The proposed simple and cost-effective method of fabricating hybrid nanostructures may pave the way for mass production of future intelligent and efficient electrochemical energy storage devices.
\end{abstract}

Keywords: pseudocapacitor; $\mathrm{ZnO}$ nanorod; manganese oxide; chemical bath deposition; anodic deposition; cyclic voltammetry

\section{Introduction}

Supercapacitors, also called electrochemical capacitors, are indispensable energy storage devices that have recently attracted great research interest from both academia and industry because they are specified to be as important as batteries for future energy storage systems. Also well-known is their usefulness in hybrid power applications requiring a high power output and/or a high cycle 
capacity, such as uninterruptible power supply units for computers, power electronics, and electric vehicles [1-3].

On the basis of their charge storage mechanisms, supercapacitors are generally classified into two main categories-electric double-layer capacitors (EDLCs) and pseudocapacitors [4,5]. EDLCs are composed of carbonaceous material such as activated carbon, carbon aerogel, etc., which have more specific surface area; unlike pseudocapacitors, which store electrical energy by the electrostatic accumulation of ionic charges in the electrical double-layer, nearby electrode, and electrolyte interfaces. Clearly, providing the material morphology with high specific surface area and enhancing its electrical conductivity are effective ways to obtain high specific capacitance in electrode material $[6,7]$. However, a pseudocapacitor commonly consists of a transition metal oxide such as $\mathrm{RuO}_{2}$ [8,9], $\mathrm{MnO}_{2}$ [10-12], $\mathrm{V}_{2} \mathrm{O}_{5}$ [13], or $\mathrm{ZnO}$ [14] possessing various valence states, which can store electronic or ionic charges not only by physical adsorption but also by reversible faradaic charge-transfer reaction occurring on the electrode surface. Theoretically, pseudocapacitors exhibit higher specific capacitance and energy density of more than 10 times as compared to EDLCs. Therefore, the pseudocapacitor has been considered to be a promising device for applications of high power density and high energy density due to their relatively fast and reversible faradic redox reactions.

Transition metal oxides, Mn-oxide, and their compounds are being widely discovered for producing supercapacitors with increased specific capacitance and energy density because manganese possesses various oxidation states and versatile properties, is low in cost, has great flexibility in structure and morphology, is abundantly found in the earth, and is more environmentally friendly than other transition metal oxides [10,15-18]. Generally, the pseudocapacitive particles are coated onto substrates as an active material to react cyclically with the electrolyte solution. Such redox reactions, however, tend to change the microstructure of the active material by repeated dissolution and reprecipitation processes, as shown in Figure 1a. After a series of electrochemical reactions, the surface morphology of the powder coating thus becomes smoother with a reduction of exposed surface area to result in the decrease in specific capacitance. Therefore, we tried to design a nanostructure that provides large surface area and mechanical support for the active material while preventing change in surface morphology, as shown in Figure 1b. It is expected that the active material can still exhibit a large surface area and possess good electrochemical stability even after repeated faradic redox reactions.

(a) electrolyte

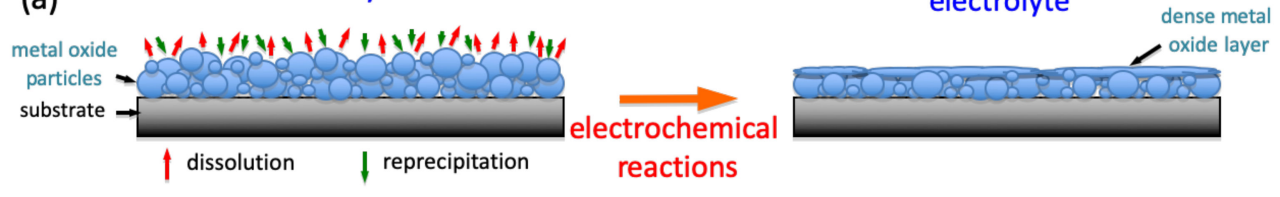

Morphological change occurs during redox reaction, resulting in the reduction of electrochemical performance

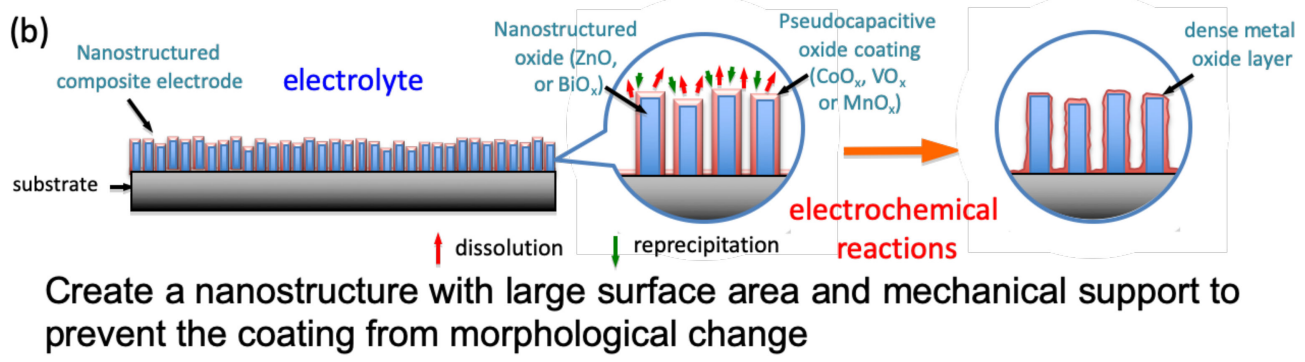

Figure 1. Schematic diagram of an electrochemical reaction between the surface of the pseudocapacitive material and the electrolyte solution. (a): Morphological change occurs during redox reaction, resulting in the reduction of electrochemical performance; (b): Creat a nanostructure with large surface area and mechanical support to prevent the coating from morphological change. 
Zinc oxide $(\mathrm{ZnO})$, as one of the most attractive multifunctional materials, is extensively studied in piezotronics and electronic devices due to its excellent electric conduction and optoelectronic properties. Additionally, $\mathrm{ZnO}$ has strong mechanical support and high electron mobility as a result of its good chemical and thermal stabilities [19-21]. ZnO nanorod arrays (e.g., 70-900 nm in rod diameter) with an aspect ratio (rod length/rod diameter) of 5-20:1 can generally deliver a high specific surface area of $4-20 \mathrm{~m}^{2} / \mathrm{g}$ [22]. Hence, various approaches for synthesizing well-aligned $\mathrm{ZnO}$ nanorod arrays on different substrates have been extensively studied, such as chemical vapor deposition (CVD) $[23,24]$, vapor-liquid-solid deposition [25,26], and solution-based growth methods [27-30]. Though the $\mathrm{MnOx} / \mathrm{ZnO}$ composite has been demonstrated to exhibit a comparable SC value [31-33], the $\mathrm{MnO}_{\mathrm{x}}$-coated $\mathrm{ZnO}$ nanostructure fabricated for supercapacitor applications has not yet been reported as a function of deposition condition. In the present study, vertically aligned $\mathrm{ZnO}$ nanorods were first synthesized by CBD as a template. Manganese oxide was subsequently coated onto the surface of $\mathrm{ZnO}$ nanorods to form a $\mathrm{MnOx}$-coated $\mathrm{ZnO}$ nanostructure by anodic deposition as a function of deposition time. The microstructure, deposited morphology, and the corresponding electrochemical properties have been systematically investigated.

\section{Materials and Methods}

\subsection{Materials}

The following compounds were used: $\mathrm{Zn}\left(\mathrm{CH}_{3} \mathrm{COO}\right)_{2} \cdot 4 \mathrm{H}_{2} \mathrm{O}$ (Showa, Japan), $\mathrm{Zn}\left(\mathrm{NO}_{3}\right)_{2} \cdot 4 \mathrm{H}_{2} \mathrm{O}$ (J. T. Baker, Phillipsburg, NJ, USA), $\mathrm{C}_{6} \mathrm{H}_{12} \mathrm{~N}_{4}$ (Alfa Aesar, Ward Hill, MA, USA) and $\mathrm{Mn}\left(\mathrm{CH}_{3} \mathrm{COO}\right)_{2} \cdot 4 \mathrm{H}_{2} \mathrm{O}$ (Acros Organics, Carlsbad, CA, USA) and further abbreviated in this report as $\mathrm{ZnA}, \mathrm{ZnN}, \mathrm{HMT}$, and MnA, respectively. All the chemicals used in this study are reagent grade with higher than $99.0 \%$ purity.

\subsection{Materials Preparation}

The zinc oxide nanorod with a vertically aligned orientation was first synthesized with various deposition times on stainless steel substrate $\left(10 \times 10 \times 1.2 \mathrm{~mm}^{3}\right)$ as a template for the deposition of $\mathrm{MnOx}$ by chemical bath deposition [34,35]. Prior to deposition, the stainless-steel substrate was ultrasonically cleaned in acetone, isopropyl alcohol, ethanol, and deionized water for $10 \mathrm{~min}$, respectively, and dried at room temperature in air. Similar to the process in the literature [34], a solution of a $0.5 \mathrm{mM}$ zinc acetate $(\mathrm{ZnA})$ dissolved in ethanol was drop-coated onto the pre-treated substrate and then heat-treated at $300{ }^{\circ} \mathrm{C}$ for $30 \mathrm{~min}$ (HTF55322C, Thermo Scientific Lindberg/Blue M, Asheville, NC) as a seed layer for $\mathrm{ZnO}$ nanostructure deposition. During the deposition process, a solution of $0.1 \mathrm{M}$ zinc nitrate $(\mathrm{ZnN})$ dissolved in hexamethylenetetramine (HMT) was prepared as a zinc source. After stirring at room temperature, ammonium hydroxide was added to the solution to adjust the $\mathrm{pH}=6$. The $\mathrm{ZnO}$ nanorods were grown by submerging the pre-seeded substrate into the zinc-containing solution at a bath temperature of $70{ }^{\circ} \mathrm{C}$ for 3-6 $\mathrm{h}$. This process gave a total amount of $\mathrm{ZnO}$ nanorod ca. $2-4 \mathrm{mg} / \mathrm{cm}^{2}$. As a template for $\mathrm{MnOx}$ deposition, the $\mathrm{ZnO}$ nanorod-deposited substrates were subsequently rinsed with deionized water and dried at room temperature in air.

Pseudocapacitive manganese oxide was deposited onto the surface of the $\mathrm{ZnO}$ nanorods in an aqueous manganese acetate (MnA) solution by anodic deposition (AD) for deposition times of 10, 20, 30, and $40 \mathrm{~s}$. The concentration of MnA solution was $0.25 \mathrm{M}$. The anodic potential was set at $0.5 \mathrm{~V}$. Subsequently, the $\mathrm{MnOx}$-coated $\mathrm{ZnO}$ nanostructured electrode was obtained by drying at room temperature in air.

\subsection{Characterizations}

The morphology examination and nanostructural analysis of the resulting core-shell electrodes were performed using scanning electron microscopy (SEM, JSM-6700F, JEOL, Tokyo, Japan) and transmission electron microscopy (TEM, 2100F, JEOL II, Tokyo, Japan), respectively. The phase 
identification was carried out by X-ray diffractometry (XRD, SRA-M18XHF, MAC Science, Yokohama, Japan). The elemental and chemical compositions were determined by energy dispersive $\mathrm{X}$-ray spectroscopy (EDS, attached to JEOL JSM-6700F) and X-ray photoelectron spectroscopy (XPS, PHI 5000 VersaProbe, ULVAC-PHI, Chigasaki, Japan), respectively. Electrochemical characterization of the electrodes was performed in a three-compartment cell by an electrochemical analyzer system (Model 727C, CH Instruments, Austin, TX, USA) at room temperature. An Ag/ $\mathrm{AgCl}$ electrode was used as the reference electrode, and a piece of platinum foil served as the counter electrode. The morphologies of the Mn/Zn-oxide coatings before and after CV were observed using scanning electron microscopy (SEM, JSM-6700F, JEOL, Tokyo, Japan).

\section{Results and Discussions}

The growth of the $\mathrm{ZnO}$ nanostructure on the stainless-steel substrate by the chemical bath deposition (CBD) method generally depends on the deposition time, temperature and $\mathrm{pH}$ condition. The X-ray diffraction patterns were utilized to confirm the crystalline structure of fabricated $\mathrm{ZnO} /$ stainless steel composite by CBD, as shown in Figure 2. The deposited $\mathrm{ZnO}$ nanostructure on stainless steel substrate as a function of various deposition time exhibited sharp and clear diffraction peaks, which are well indexed based on crystalline hexagonal wurtzite phase of $\mathrm{ZnO}$ (JCPDS card no.: 80-0075). The strong diffraction peak of (002) planar indicated that the $\mathrm{ZnO}$ nanostructure appeared with the preferred hexagonal orientation of the $c$-axis. The heterogeneous growth of the $\mathrm{ZnO}$ nanostructure was enhanced with the increase in deposition time. The crystallinity was further estimated using the Scherrer equation. Figure 3 shows the crystallite size of $\mathrm{ZnO}$ nanostructures as a function of various deposition time. Note that the crystallite size increased as the deposition time increased, suggesting that the enhancement in the crystalline growth of the preferred orientation of the $\mathrm{ZnO}$ nanostructure corresponds with prolonging the deposition time.

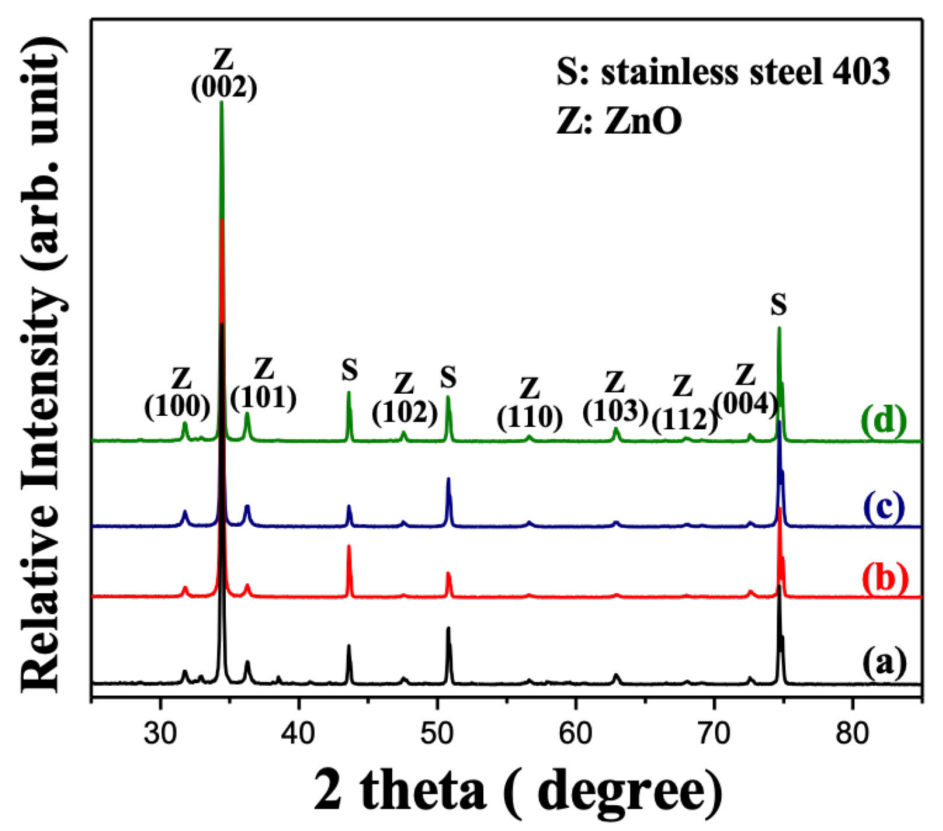

Figure 2. X-ray diffraction (XRD) patterns of the $\mathrm{ZnO}$ nanorods deposited under growth condition of $\mathrm{pH}=6$ by chemical bath deposition at $70{ }^{\circ} \mathrm{C}$ for (a) 3 , (b) 4, (c) 5 , and (d) $6 \mathrm{~h}$. 


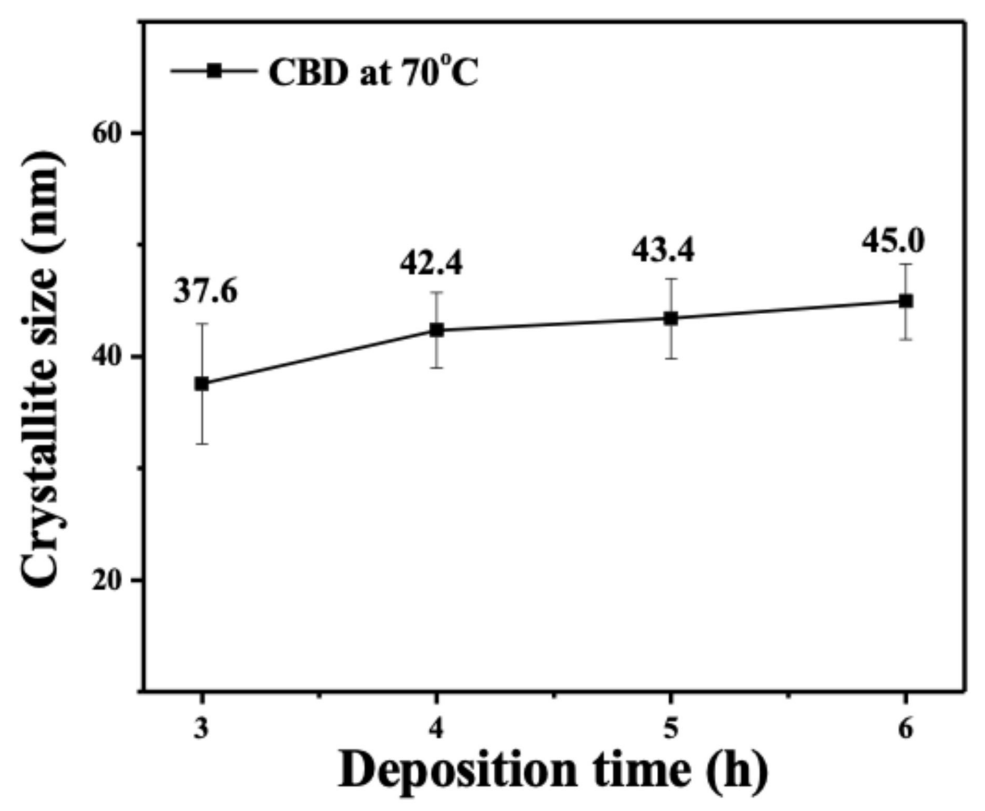

Figure 3. Crystallite size of the $\mathrm{ZnO}$ nanorods deposited under growth condition of $\mathrm{pH}=6$ by chemical bath deposition (CBD) at $70{ }^{\circ} \mathrm{C}$ as a function of deposition time.

Figure 4a-d shows the top-view SEM images of the bare $\mathrm{ZnO}$ nanostructure via $\mathrm{CBD}$ at $70{ }^{\circ} \mathrm{C}$ for various deposition times. From the micrograph image, the $\mathrm{ZnO}$ nanostructure revealed randomly orientated nanorods with the preferred vertical orientation, which agrees with the results of XRD as shown in Figure 2. Furthermore, it was observed that the dimension of the $\mathrm{ZnO}$ nanorods increased with the increase in deposition time. Though not shown here yet, the $\mathrm{ZnO}$ nanorod after $6 \mathrm{~h}$ of deposition exhibited better capacitive properties; thus, the $6 \mathrm{~h}$ grown $\mathrm{ZnO}$ template was employed for the anodic deposition of the pseudocapacitive MnOx.
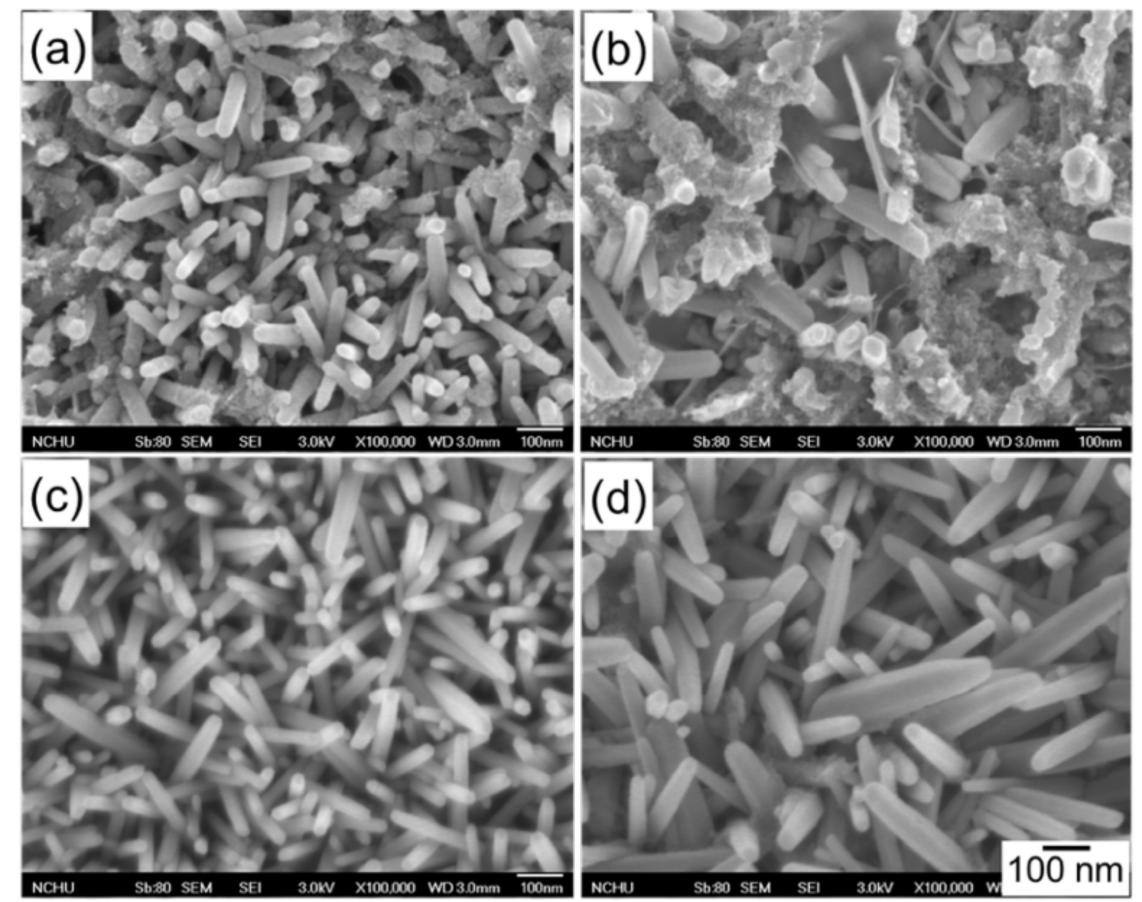

Figure 4. Scanning electron microscopy (SEM) micrographs of the $\mathrm{ZnO}$ nanorods deposited under growth condition of $\mathrm{pH}=6$ by CBD at $70{ }^{\circ} \mathrm{C}$ for deposition times of (a) 3, (b) 4, (c) 5, and (d) $6 \mathrm{~h}$. 
Figure 5 shows the top-view SEM micrographs of the MnOx-coated $\mathrm{ZnO}$ nanorod as a function of $\mathrm{MnOx}$ deposition time. Note that the amount of $\mathrm{MnOx}$ coating increased with the increase in deposition time, and almost covered the $\mathrm{ZnO}$ nanorods after $40 \mathrm{~s}$ of anodic deposition (AD). However, in Figure 5a,b, the AD MnOx coating is imperceptible in the $10 \mathrm{~s}$ and $20 \mathrm{~s}$ deposited samples in the SEM images. Although not shown here, even after $40 \mathrm{~s}$ of $\mathrm{MnOx}$ deposition, the resolution of XRD is also unable to reveal the presence of $\mathrm{MnOx}$ on $\mathrm{ZnO}$ nanorods due to the small amount of coating. Therefore, EDX and XPS (to be discussed in Figure 11) spectra were further carried out for the elemental and oxidation state analyses, respectively, to confirm the $\mathrm{MnOx}$ deposition. Figure 5e shows respectively the EDX spectrum and elemental composition of the MnOx-deposited $\mathrm{ZnO}$ nanorod at a deposition time of $10 \mathrm{~s}$. Manganese signals were detected in the MnOx-coated $\mathrm{ZnO}$ nanorod after just $10 \mathrm{~s}$ of deposition, revealing that the $\mathrm{MnOx}$ can be coated onto the surface of the $\mathrm{ZnO}$ nanorods in a relatively short deposition time.
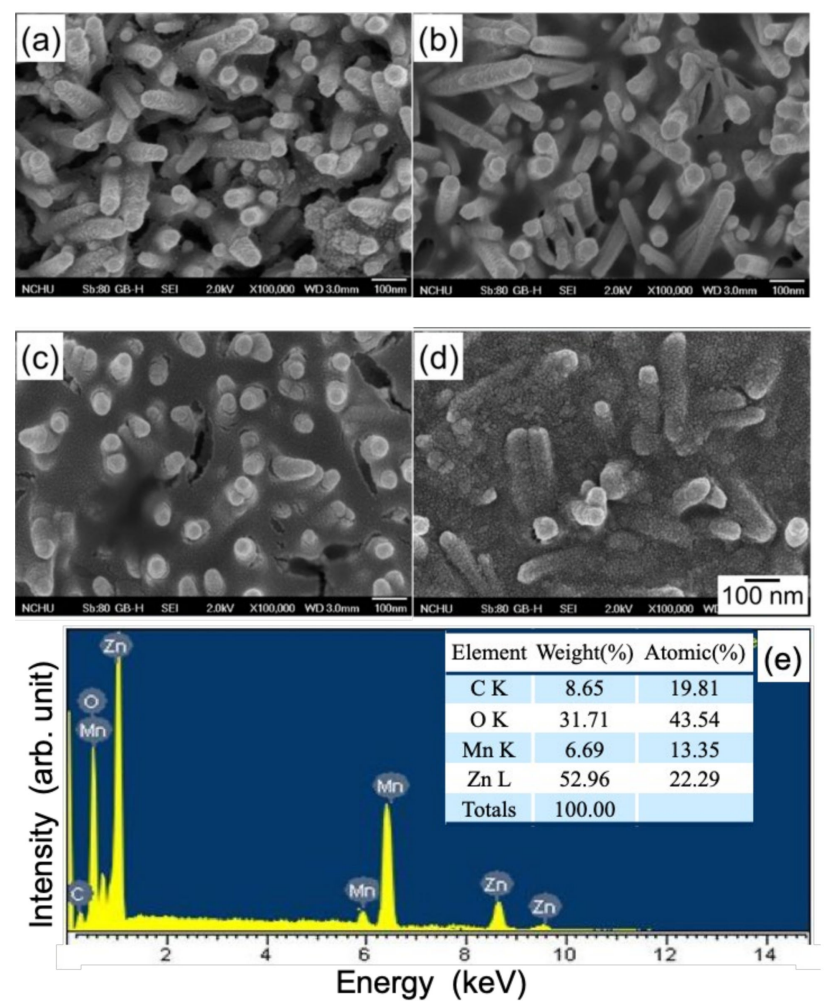

Figure 5. SEM micrographs of the MnOx-coated $\mathrm{ZnO}$ nanorod for MnOx deposition times of (a) 10, (b) 20, (c) 30, and (d) $40 \mathrm{~s}$. (e) shows the EDX spectrum and elemental composition of the MnOx-coated $\mathrm{ZnO}$ nanorod at a deposition time of $10 \mathrm{~s}$. The $\mathrm{MnOx}$ was coated by anodic deposition in a $0.25 \mathrm{M}$ $\mathrm{Mn}\left(\mathrm{CH}_{3} \mathrm{COO}\right)_{2} \cdot 4 \mathrm{H}_{2} \mathrm{O}$ solution at $25^{\circ} \mathrm{C}$.

To further reveal the details of the MnOx deposition, the morphology of the MnOx-coated $\mathrm{ZnO}$ nanorod, as well as the stainless-steel substrate, was confirmed by TEM observation in the present study. Figure 6 shows the cross-sectional TEM micrographs of $\mathrm{ZnO}$ nanorods with MnOx coatings after $\mathrm{MnOx}$ deposition, with different deposition times. Such advanced electron microscopy related techniques provide an effective route for examining the coverage uniformity and thickness of the AD $\mathrm{MnOx}$ coating, as well as the interface between the MnOx coating and the $\mathrm{ZnO}$ template. Note that the seed layer consisted of randomly distributed $\mathrm{ZnO}$ nanocrystallites with a thickness of ca. 80-100 nm (Figure 6a,c). The CBD ZnO nanorods with ca. 20-45 nm in diameter were then revealed to grow in a spatially confined mode due to the high density of seeds, forcing a vertical alignment during nanorod formation [36]. Moreover, a translucent thin layer was observed on the surface of the $\mathrm{ZnO}$ nanorods, suggesting an extremely poor crystalline AD MnOx coating. Almost all the surfaces of the 
$\mathrm{ZnO}$ nanorod were covered with a relatively uniform MnOx coating. The thicknesses of the $10 \mathrm{~s}$ and $20 \mathrm{~s}$ deposited MnOx coatings were, respectively, ca. 3-4 nm and 7-8 nm. Figure 6b,d shows an increasing trend with prolonging the AD time. Indeed, these results are in agreement with the SEM results.
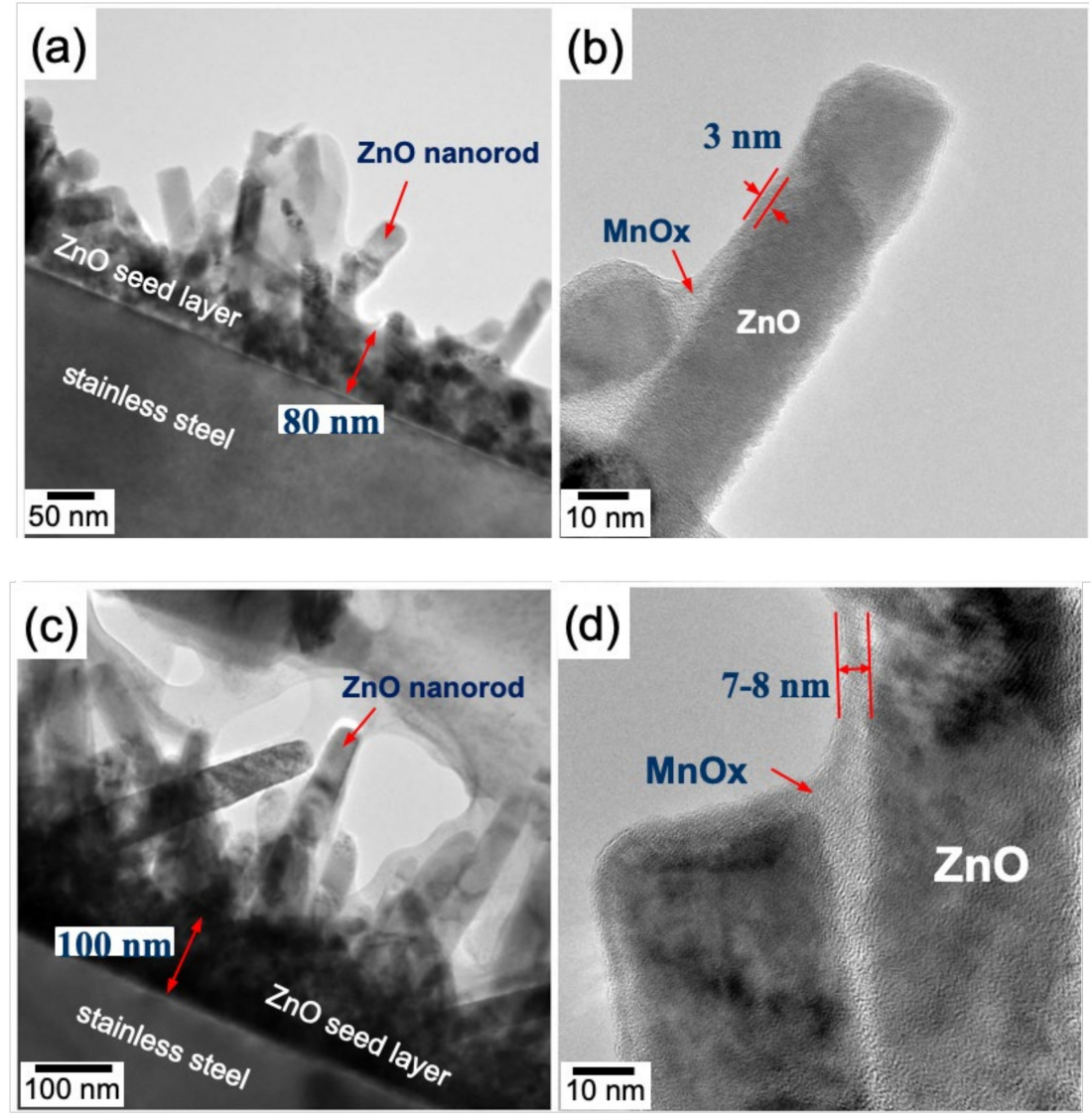

Figure 6. Cross-sectional TEM micrographs of the MnOx-deposited $\mathrm{ZnO}$ nanorod at deposition times of $(\mathbf{a}, \mathbf{b}) 10 \mathrm{~s}$ and $(\mathbf{c}, \mathbf{d}) 20 \mathrm{~s}$. The $\mathrm{MnOx}$ was coated by anodic deposition in a $0.25 \mathrm{M} \mathrm{Mn}\left(\mathrm{CH}_{3} \mathrm{COO}\right)_{2} \cdot 4 \mathrm{H}_{2} \mathrm{O}$ solution at $25^{\circ} \mathrm{C}$.

The pseudocapacitive characteristics of the $\mathrm{ZnO}$ nanorod with and without $\mathrm{MnOx}$ coating were analyzed by cyclic voltammetry and life tests. Figure 7 shows CV curves of the uncoated $\mathrm{ZnO}$ nanorod in $1.0 \mathrm{M} \mathrm{Na}_{2} \mathrm{SO}_{4}$ in the range of 0 to $1.0 \mathrm{~V}$ with a scan rate of $25 \mathrm{mV} / \mathrm{s}$ as a function of CBD growth time before the preparation of $\mathrm{MnOx}$-coated equivalent. Note that the $\mathrm{CV}$ curves were almost rectangular in shape, revealing a typical capacitive behavior with a charging current in both scanning directions across the potential range of 0 to $1.0 \mathrm{~V}$. The $\mathrm{CV}$ curves demonstrated that the uncoated $\mathrm{ZnO}$ nanorods had good redox reversibility. Moreover, the area under the CV curve can be used to estimate the specific capacitance (SC) of the system according to the following equations [37-40]:

$$
\begin{gathered}
C=\frac{1}{\Delta V(d V / d t)} \int I d V \\
C_{s p}=\frac{A}{\Delta V \times v \times m}
\end{gathered}
$$

where $C$ and $C_{s p}$ are the integral capacitance and specific capacitance of the electrode, respectively. $d V / d t$ is the voltage scan rate, $I$ is the voltammetric current, $A$ is the integral area of the cyclic voltammogram loop, $\Delta V$ is the sweep potential window, $v$ is the scan rate, and $m$ is the mass of the active materials at the electrode. The SCs of the uncoated $\mathrm{ZnO}$ nanorod were measured from the 50th CV tests. The SCs of the uncoated $\mathrm{ZnO}$ nanorods were 25, 27, 31, and $33 \mathrm{~F} / \mathrm{g}$ for $\mathrm{CBD}$ grow times of 3, 4, 5, and $6 \mathrm{~h}$, 
respectively. Though the $\mathrm{ZnO}$ nanorods exhibited capacitive behaviors, the SCs were still relatively low in comparison with those of pseudocapacitive materials, such as $\mathrm{RuO}_{2}, \mathrm{MnO}_{2}, \mathrm{~V}_{2} \mathrm{O}_{5}$ [10-13]. The $6 \mathrm{~h}$ grown $\mathrm{ZnO}$ nanorod possessing the highest $\mathrm{SC}$ value was used as the template for the $\mathrm{MnOx}$ deposition. Figure 8 shows $\mathrm{CV}$ curves of the MnOx-coated $\mathrm{ZnO}$ nanorod in $1.0 \mathrm{M} \mathrm{Na}_{2} \mathrm{SO}_{4}$ in the range of 0 to $1.0 \mathrm{~V}$ with a scan rate of $25 \mathrm{mV} / \mathrm{s}$ as a function of MnOx AD times. Similarly, the MnOx-coated samples having almost rectangular CV curves revealed a typical capacitive behavior and a good redox reversibility. Note that the SCs of the MnOx-coated ZnO nanorods were estimated to be 222, 194, 136, and $112 \mathrm{~F} / \mathrm{g}$ for the deposition times of 10, 20,30 and $40 \mathrm{~s}$, respectively. The SC decreased with the increase of $\mathrm{MnOx} \mathrm{AD}$ time. That is, the thicker MnOx coating may result in the decrease of specific capacitance in this system. An appropriate thickness of MnOx coating was thought to provide a more effective surface area for faradaic redox reaction, thus elevating the specific capacitance of the active material.

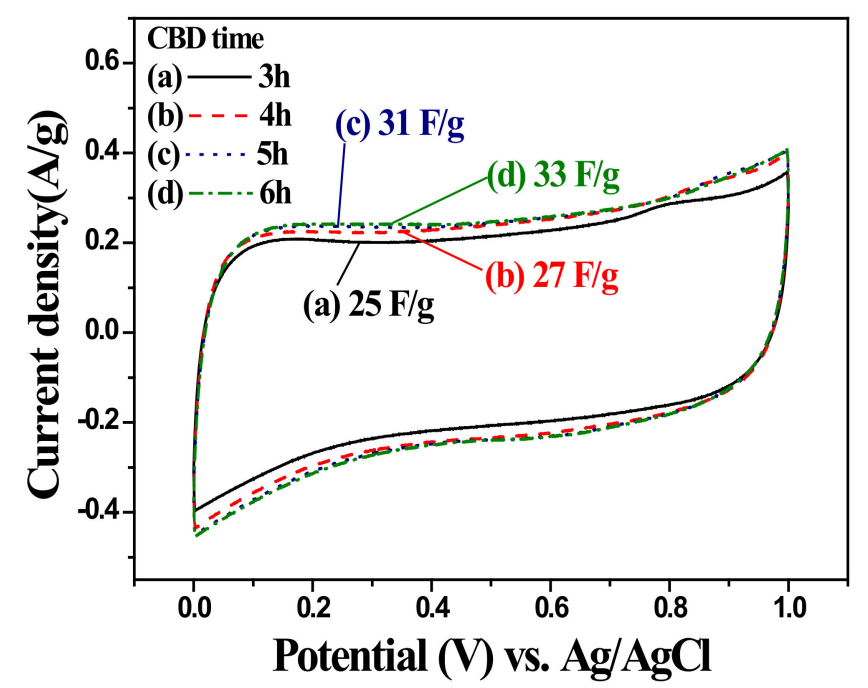

Figure 7. Cyclic voltammograms of $\mathrm{ZnO}$ nanorod measured from the 50 th cycle in $1.0 \mathrm{M} \mathrm{Na}_{2} \mathrm{SO}_{4}$ electrolyte at a scan rate of $25 \mathrm{mV} / \mathrm{s}$ as a function of CBD time. The $\mathrm{ZnO}$ nanorods were deposited under growth condition of $\mathrm{pH}=6$ by $\mathrm{CBD}$ at $70^{\circ} \mathrm{C}$.

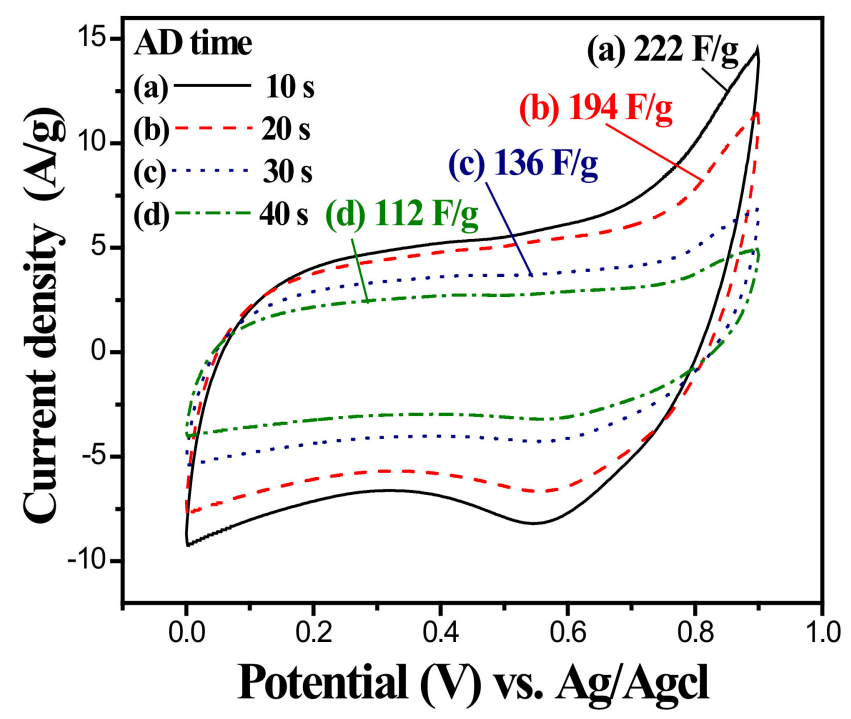

Figure 8. Cyclic voltammograms of $\mathrm{MnOx}$-coated $\mathrm{ZnO}$ nanorod measured from the 50 th cycle in $1.0 \mathrm{M}$ $\mathrm{Na}_{2} \mathrm{SO}_{4}$ electrolyte at a scan rate of $25 \mathrm{mV} / \mathrm{s}$ as a function of anodic deposition time. The MnOx was coated in a $0.25 \mathrm{M} \mathrm{Mn}\left(\mathrm{CH}_{3} \mathrm{COO}\right)_{2} \cdot 4 \mathrm{H}_{2} \mathrm{O}$ solution at $25^{\circ} \mathrm{C}$. 
The electrochemical stability of the $\mathrm{MnOx}$-coated $\mathrm{ZnO}$ nanorod was investigated by repeating the $\mathrm{CV}$ test at a scan rate of $100 \mathrm{mV} / \mathrm{s}$ for 1200 cycles. Figure 9 shows the long-term cycle performance of the $\mathrm{MnOx}$-coated $\mathrm{ZnO}$ nanorod in $1.0 \mathrm{M} \mathrm{Na}_{2} \mathrm{SO}_{4}$ electrolyte as a function of MnOx AD time. Because the slow diffusion rate of electrolyte ions gains access to the available sites by intercalation and/or absorption [41], the higher the scan rate, the lower the measured SC (comparing to the data in Figure 8). The SC of all the samples increases dramatically before 100 cycles of CV, implying that the surface of the coatings was activated at the initial stage. An imperceptible decline in SC of the samples with increased $\mathrm{CV}$ cycle number can be observed after 200 cycles. That is, the capacitance of the MnOx-coated $\mathrm{ZnO}$ nanorod tended to decline slightly after the activation of the initial 200 cycles until the cycle number increased to 1200 . The cycling efficiencies (minimum/the maximum SC ratio) of the samples in the 1200-cycle life tests are also indicated in the figure. In the literature, without template/scaffold supports, $\mathrm{MnOx}$ coatings tend to change the surface morphology into denser and smoother structures by the adsorption/desorption or the intercalation/de-intercalation process, causing a decline in SC during the repeated charging/discharging process [42]. As shown in the figure, the data indicates that the $\mathrm{ZnO}$ nanorod can significantly improve the cycling stability of the MnOx coatings up to an efficiency higher than $97.5 \%$. The MnOx-coated $\mathrm{ZnO}$ nanorods possess relatively good efficiencies with a good electrochemical performance for supercapacitors. It is believed that the $\mathrm{ZnO}$ nanorod provided a template for avoiding the significant change in surface morphology of the MnOx coating after long-term repetitive cycling tests, resulting in high electrochemical stability.

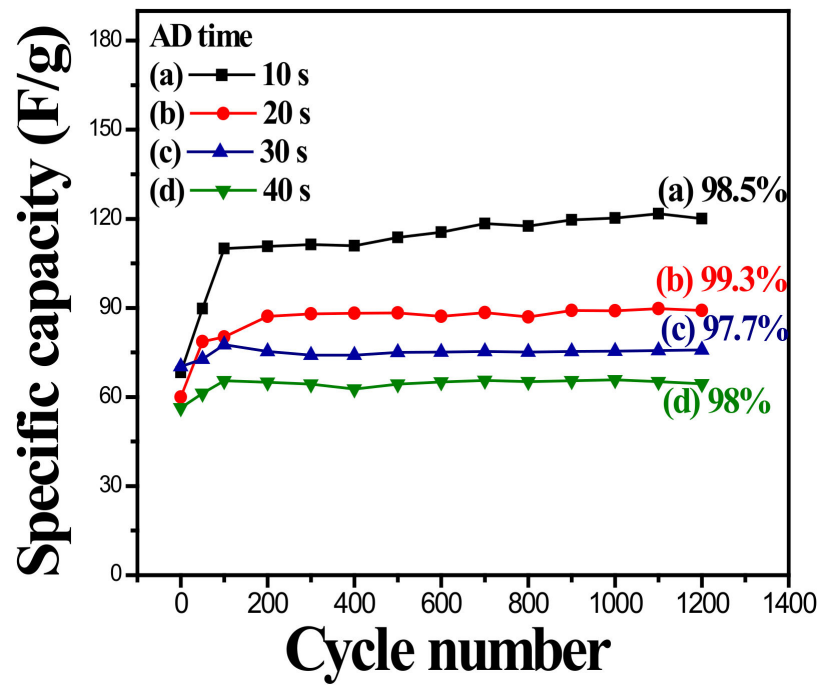

Figure 9. Specific capacitance of $\mathrm{MnOx}$-coated $\mathrm{ZnO}$ nanorod measured in $1.0 \mathrm{M} \mathrm{Na}_{2} \mathrm{SO}_{4}$ electrolyte at a scan rate of $100 \mathrm{mV} / \mathrm{s}$ at various anodic deposition time as a function of cycle number.

To clarify the role of the $\mathrm{ZnO}$ nanorod during the electrochemical reactions in this system, the changes of electronic structures or chemical valence state of each element of the $\mathrm{ZnO}$ template with and without $\mathrm{MnOx}$ coating before and after charging reactions were carried out by XPS analyses. Figure 10 shows the $\mathrm{Zn} \mathrm{2p3/2} \mathrm{and} \mathrm{O} \mathrm{1s} \mathrm{XPS} \mathrm{spectra} \mathrm{of} \mathrm{the} \mathrm{uncoated} \mathrm{ZnO} \mathrm{nanorod} \mathrm{before} \mathrm{and} \mathrm{after}$ the CV test. As seen in Figure 10a, the binding energy of the Zn 2p3/2 peak was slightly shifted from $1021.8 \mathrm{eV}$ to $1022.0 \mathrm{eV}$ after the charging reaction. Such a small change in the oxidation state of $\mathrm{Zn}^{2+}$ in $\mathrm{ZnO}$, an almost negligible change during a faradaic redox reaction, implies that the $\mathrm{ZnO}$ nanorod has low specific capacitance. On the other hand, the high-resolution $\mathrm{O}$ 1s spectrum (Figure $10 \mathrm{~b}$ ) can be deconvoluted into two peaks of the uncoated $\mathrm{Zn}-\mathrm{O}$ bond (530.2 eV) and H-O-H bond (surface-adsorbed water, $532.6 \mathrm{eV}$ ). As the result suggests, the presence of adsorbed $\mathrm{H}_{2} \mathrm{O}$ and $\mathrm{O}_{2}$ on the surface of the $\mathrm{ZnO}$ nanorod is highly inhibitive of SC. Figure 11 shows the $\mathrm{Zn} \mathrm{2p3/2,} \mathrm{Mn} \mathrm{2p3/2,} \mathrm{and} \mathrm{O} \mathrm{1s} \mathrm{XPS}$ spectra of the MnOx-coated $\mathrm{ZnO}$ nanorod before and after the $\mathrm{CV}$ test. As shown in Figure 11a, 
the shift in the $\mathrm{Zn} 2 \mathrm{p} 3 / 2$ peak from $1021.8 \mathrm{eV}$ to $1021.2 \mathrm{eV}$ is associated with the change of $\mathrm{Zn}(+2)$ to $\mathrm{Zn}(0)$, which indicates that the $\mathrm{MnOx}$ coating may reduce nanorod $\mathrm{ZnO}$ to $\mathrm{Zn}$ during repetitive $\mathrm{CV}$ cycles. Moreover, the Mn 2p3/2 peak at a binding energy of $641.2 \mathrm{eV}$ and $640.8 \mathrm{eV}$, Figure 11b, of the Mn-coated $\mathrm{ZnO}$ nanorod, were addressed as oxidation states of $+2.66\left(\mathrm{Mn}_{3} \mathrm{O}_{4}\right)$ and $+2(\mathrm{MnO})$, respectively. This suggests that the $\mathrm{MnOx}$ coating changed from $\mathrm{Mn}_{3} \mathrm{O}_{4}$ to $\mathrm{MnO}$ after repetitive charging/discharging reactions. As reported in the literature, pseudocapacitive $\mathrm{Mn}_{3} \mathrm{O}_{4}$ are generally expected to react to $\mathrm{MnO}_{2}$ after experiencing a series of CV tests [12]. In the case of the $\mathrm{MnOx}$ coating on the $\mathrm{ZnO}$ nanorod, the reaction of the $\mathrm{MnOx}$ coating from $\mathrm{Mn}_{3} \mathrm{O}_{4}$ to $\mathrm{MnO}$ was influenced by the combination of the pseudocapacitive reaction with the electrolyte solution and the redox reaction with the $\mathrm{ZnO}$ nanorod. Such interactions may cause the limited specific capacitance of the MnOx coating. In the present study, however, the design of the pseudocapacitor electrode based on MnOx-coated $\mathrm{ZnO}$ nanostructured material has been proposed for a promising solution for the applications of a supercapacitor with high electrochemical stability.
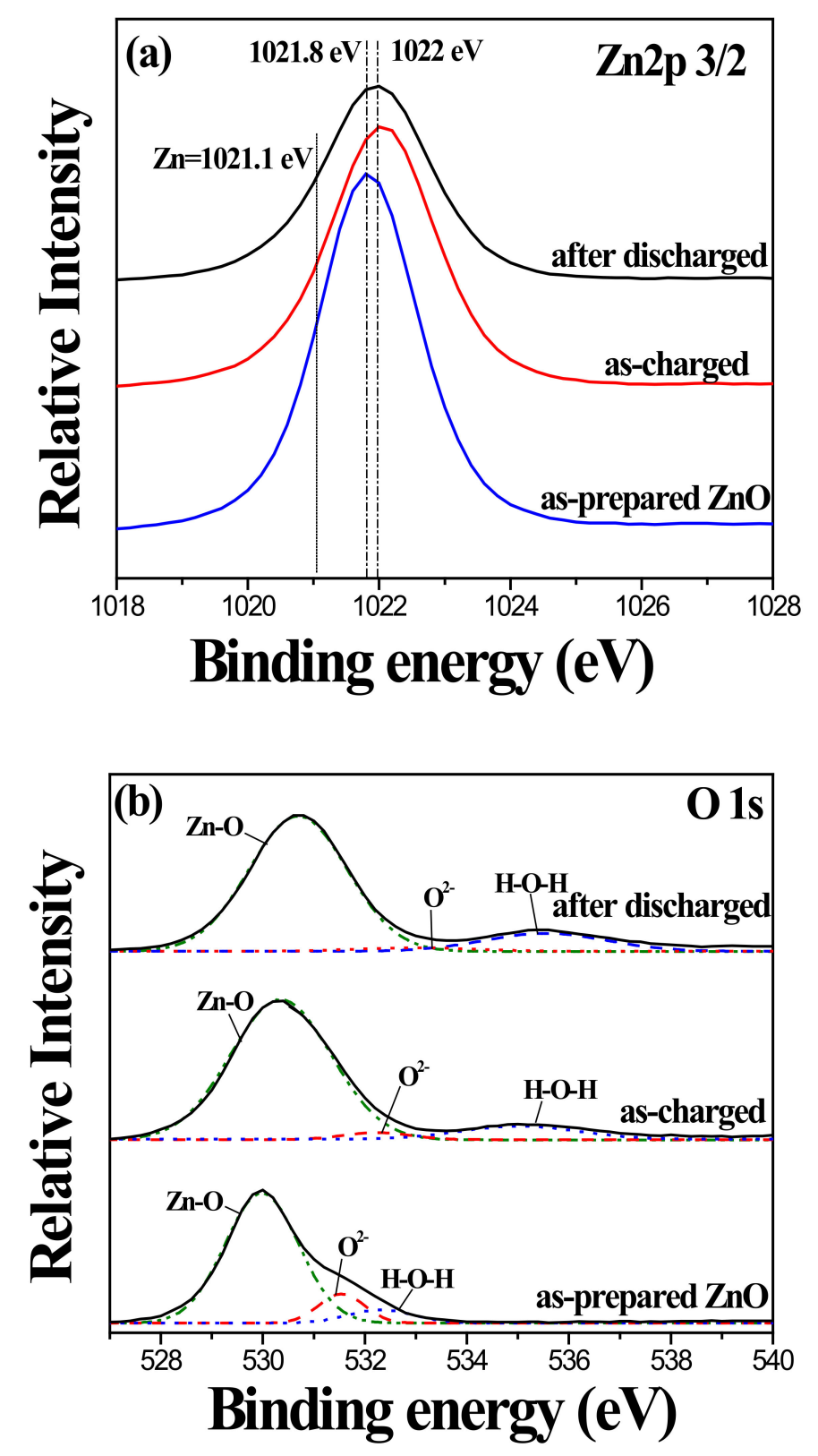

Figure 10. (a) Zn 2p 3/2 and (b) O 1s XPS spectra of uncoated ZnO nanorod before and after CV test. 

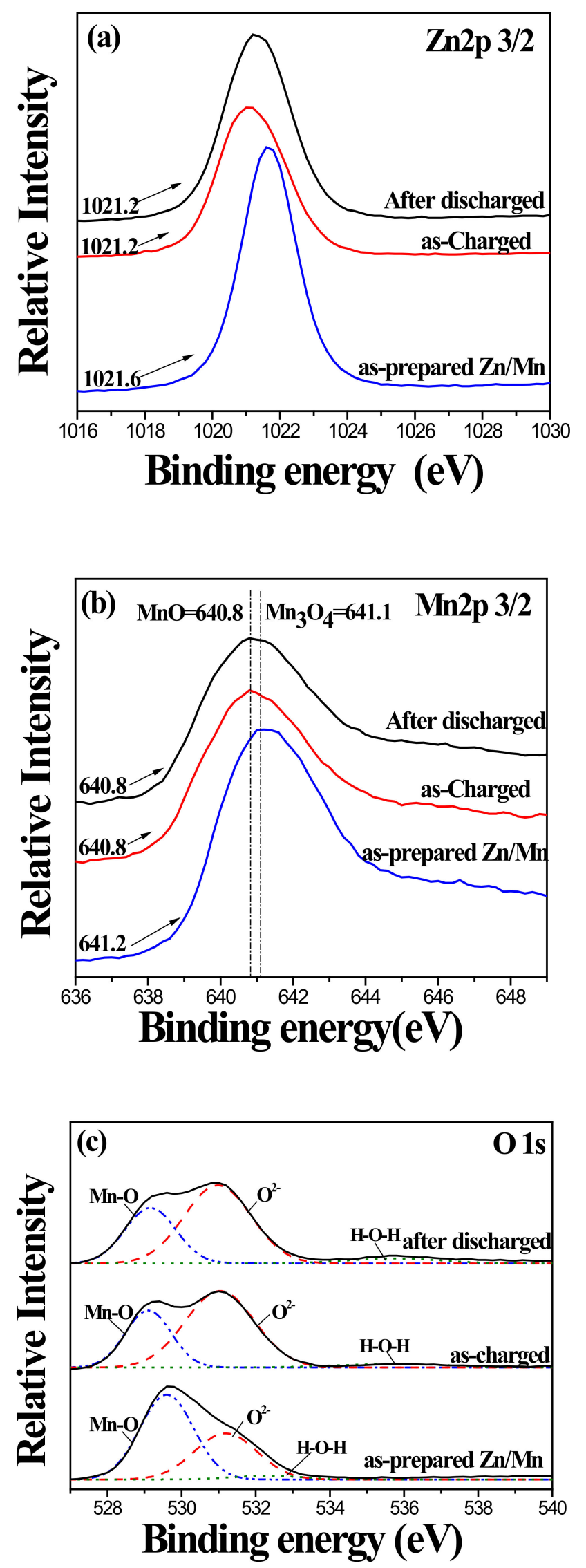

Figure 11. (a) Zn 2p 3/2, (b) Mn 2p 3/2 and (c) O 1s XPS spectra of MnOx-coated ZnO nanorod before and after $\mathrm{CV}$ test. 


\section{Conclusions}

The MnOx-Coated $\mathrm{ZnO}$ nanostructure was successfully prepared via a combination of chemical bath deposition and anodic deposition for use as a potential pseudocapacitor electrode material with excellent electrochemical stability. As a template for pseudocapacitive MnOx coating, vertically grown wurtzite $\mathrm{ZnO}$ nanorods on a stainless-steel substrate provided an efficiently mechanical scaffold for the electrochemical reaction of active materials. The AD MnOx coating with $3-8 \mathrm{~nm}$ in thickness and a good coverage exhibited an acceptable specific capacitance of $222 \mathrm{~F} / \mathrm{g}$ for the deposition times of $10 \mathrm{~s}$. Furthermore, the nanostructural design of the pseudocapacitor electrode based on $\mathrm{MnOx}$-coated $\mathrm{ZnO}$ material possessed better behavior of electrochemical energy storage, with higher cycling efficiencies of better than $97.5 \%$ after $1200 \mathrm{CV}$ cycles and can be considered as a highly promising candidate for a pseudocapacitor.

Author Contributions: Conceptualization, C.-Y.C.; methodology, C.-Y.C. and C.-K.L.; formal analysis, H.-C.C., Y.-R.L., and G.-J.L.; investigation, H.-C.C., G.-J.L., and L.K.; resources, A.F., J.J.W., and S.A.; writing-original draft preparation, C.-Y.C.; writing—review and editing, C.-Y.C. C.-K.L., and A.F.; supervision, C.-Y.C. and C.-K.L.; project administration, C.-Y.C.; funding acquisition, C.-Y.C. All authors have read and agreed to the published version of the manuscript.

Funding: This research was funded by the Ministry of Science and Technology of Taiwan Grant Nos. MOST 106-2221-E-035-035-MY2, 107-2218-E-035-010, and 108-2918-I-035-004.

Acknowledgments: The authors would like to thank the Ministry of Science and Technology of Taiwan for financially supporting this work. The authors also appreciate the Precision Instrument Support Center of Feng Chia University for providing the measurement facilities.

Conflicts of Interest: The authors declare no conflict of interest.

\section{References}

1. Conway, B.E. Transition from "Supercapacitor" to "battery" behavior in electrochemical energy storage. J. Electrochem. Soc. 1991, 138, 1539-1548. [CrossRef]

2. Sarangapani, S.; Tilak, B.V.; Chen, C.P. Materials for electrochemical capacitors. J. Electrochem. Soc. 1996, 143, 3791-3799. [CrossRef]

3. Prasad, K.R.; Miura, N. Electrochemically synthesized $\mathrm{MnO}_{2}$-based mixed oxides for high performance redox supercapacitors. Electrochem. Commun. 2004, 6, 1004-1008. [CrossRef]

4. Lee, C.Y.; Tsai, H.M.; Chuang, H.J.; Li, S.Y.; Lin, P.; Tseng, T.Y. Characteristics and electrochemical performance of supercapacitors with manganese oxide-carbon nanotube nanocomposite electrodes. J. Electrochem. Soc. 2005, 152, A716-A720. [CrossRef]

5. Jang, J.H.; Kato, A.; Machida, K.; Naoi, K. Supercapacitor performance of hydrous ruthenium oxide electrodes prepared by electrophoretic deposition. J. Electrochem. Soc. 2006, 153, A321-A328. [CrossRef]

6. Li, X.; Jiang, L.; Zhou, C.; Liu, J.; Zeng, H. Integrating large specific surface area and high conductivity in hydrogenated $\mathrm{NiCo}_{2} \mathrm{O}_{4}$ double-shell hollow spheres to improve supercapacitors. NPG Asia Mater. 2015, 7, e165. [CrossRef]

7. Li, B.; Zheng, M.; Xue, H.; Pang, H. High performance electrochemical capacitor materials focusing on nickel based materials. Inorg. Chem. Front. 2016, 3, 175-202. [CrossRef]

8. Trasatti, S.; Buzzanca, G. Ruthenium dioxide: A new interesting electrode material. Solid state structure and electrochemical behavior. J. Electroanal. Chem. Interfacial Electrochem. 1971, 29, A1-A5. [CrossRef]

9. Hu, C.-C.; Chang, K.-H.; Lin, M.-C.; Wu, Y.-T. Design and tailoring of the nanotubular arrayed architecture of hydrous $\mathrm{RuO}_{2}$ for next generation supercapacitors. Nano Lett. 2006, 6, 2690-2695. [CrossRef]

10. Lee, H.; Goodenough, J. Supercapacitor behavior with KCl electrolyte. J. Solid State Chem. 1999, 144, $220-223$. [CrossRef]

11. Hung, C.J.; Hung, J.H.; Lin, P.; Tseng, T.Y. Electrophoretic fabrication and characterizations of manganese oxide/carbon nanotube nanocomposite pseudocapacitors. J. Electrochem. Soc. 2011, 158, A942-A947. [CrossRef] 
12. Chen, C.Y.; Lyu, Y.R.; Su, C.Y.; Lin, H.M.; Lin, C.K. Characterization of spray pyrolyzed manganese oxide powders deposited by electrophoretic deposition technique. Surf. Coat. Technol. 2007, 202, 1277-1281. [CrossRef]

13. Chen, Z.; Augustyn, V.; Wen, J.; Zhang, Y.; Shen, M.; Dunn, B.; Lu, Y. High-performance supercapacitors based on intertwined $\mathrm{CNT} / \mathrm{V}_{2} \mathrm{O}_{5}$ nanowire nanocomposites. Adv. Mater. 2011, 23, 791-795. [CrossRef] [PubMed]

14. Kalpana, D.; Omkumar, K.S.; Kumar, S.S.; Renganathan, N.G. A novel high power symmetric ZnO/carbon aerogel composite electrode for electrochemical supercapacitor. Electrochim. Acta 2006, 52, 1309-1315. [CrossRef]

15. Pang, S.-C.; Anderson, M.A.; Chapman, T.W. Novel electrode materials for thin-film ultracapacitors: Comparison of electrochemical properties of sol-gel-derived and electrodeposited manganese dioxide. J. Electrochem. Soc. 2000, 147, 444-450. [CrossRef]

16. Lee, H.Y.; Kim, S.W.; Lee, H.Y. Expansion of active site area and improvement of kinetic reversibility in electrochemical pseudocapacitor electrode. Electrochem. Solid State Lett. 2001, 4, A19-A22. [CrossRef]

17. Hu, C.-C.; Chen, W.-C.; Chang, K.-H. How to achieve maximum utilization of hydrous ruthenium oxide for supercapacitors. J. Electrochem. Soc. 2004, 151, A281-A290. [CrossRef]

18. Bazhan, Z.; Ghodsi, F.E.; Mazloom, J. The surface wettability and improved electrochemical performance of nanostructured $\mathrm{Co}_{x} \mathrm{Fe}_{3-x} \mathrm{O}_{4}$ thin film. Surf. Coat. Technol. 2017, 309, 554-562. [CrossRef]

19. Nomura, K.; Ohta, H.; Ueda, K.; Kamiya, T.; Hirano, M.; Hosono, H. Thin-film transistor fabricated in single-crystalline transparent oxide semiconductor. Science 2003, 300, 1269-1270. [CrossRef]

20. Yoshida, T.; Komatsu, D.; Shimokawa, N.; Minoura, H. Mechanism of cathodic electrodeposition of zinc oxide thin films from aqueous zinc nitrate baths. Thin Solid Films 2004, 451-452, 166-169. [CrossRef]

21. Tsay, C.-Y.; Fan, K.-S.; Chen, S.-H.; Tsai, C.-H. Preparation and characterization of ZnO transparent semiconductor thin films by sol-gel method. J. Alloys Compd. 2010, 495, 126-130. [CrossRef]

22. Luo, S.; Liu, C.; Wan, Y.; Li, W.; Ma, C.; Liu, S.; Heeres, H.J.; Zheng, W.; Seshan, K.; He, S. Self-assembly of single-crystal $\mathrm{ZnO}$ nanorod arrays on flexible activated carbon fibers substrates and the superior photocatalytic degradation activity. Appl. Surf. Sci. 2020, 513, 145878. [CrossRef]

23. Wu, J.J.; Liu, S.C. Low-temperature growth of well-aligned $\mathrm{ZnO}$ nanorods by chemical vapor deposition. Adv. Mater. 2002, 14, 215-218. [CrossRef]

24. Hu, P.-S.; Wu, C.-E.; Chen, G.-L. ZnO micro/nanostructures grown on sapphire substrates using low-temperature vapor-trapped thermal chemical vapor deposition: Structural and optical properties. Materials 2018, 11, 3. [CrossRef]

25. Gao, P.; Wang, Z.L. Self-assembled nanowire-nanoribbon junction arrays of ZnO. J. Phys. Chem. B 2002, 106, 12653-12658. [CrossRef]

26. Wang, S.; Song, J.; Li, P.; Ryou, J.H.; Dupuis, R.D.; Summers, C.J.; Wang, Z.L. Growth of uniformly aligned $\mathrm{ZnO}$ nanowire heterojunction arrays on $\mathrm{GaN}, \mathrm{AlN}$, and $\mathrm{Al}_{0.5} \mathrm{Ga}_{0.5} \mathrm{~N}$ substrates. J. Am. Chem. Soc. 2005, 127, 7920-7923. [CrossRef]

27. Vayssieres, L. Growth of arrayed nanorods and nanowires of $\mathrm{ZnO}$ from aqueous solutions. Adv. Mater. 2003, 15, 464-466. [CrossRef]

28. Zheng, Z.K.; Lim, Z.S.; Peng, Y.; You, L.; Chen, L.; Wang, J. General route to ZnO nanorod arrays on conducting substrates via galvanic-cell-based approach. Sci. Rep. 2013, 3, 2434. [CrossRef]

29. Fudzi, L.M.; Zainal, Z.; Lim, H.N.; Chang, S.-K.; Holi, A.M.; Ali, M.S. Effect of temperature and growth time on vertically aligned $\mathrm{ZnO}$ nanorods by simplified hydrothermal technique for photoelectrochemical cells. Materials 2018, 11, 704. [CrossRef]

30. Alarabi, A.; Zeng, Z.; Gao, Y.; Gao, S.; Jiao, S.; Wang, D.; Wang, J. Influence of different substrates on ZnO nanorod arrays properties. Solid State Sci. 2018, 85, 21-25. [CrossRef]

31. He, Y.-B.; Li, G.-R.; Wang, Z.-L.; Su, C.-Y.; Tong, Y.-X. Single-crystal ZnO nanorod/amorphous and nanoporous metal oxide shell composites: Controllable electrochemical synthesis and enhanced supercapacitor performances. Energy Environ. Sci. 2011, 4, 1288-1292. [CrossRef]

32. Chen, C.-Y.; Chiang, C.-Y.; Shih, S.-J.; Tsay, C.-Y.; Lin, C.-K. High Supercapacitive Performance of Sol-Gel ZnO-doped Manganese Oxide Coatings. Thin Solid Films 2013, 528, 61-66. [CrossRef] 
33. Ma, W.; Shi, Q.; Nan, H.; Hu, Q.; Zheng, X.; Geng, B.; Zhang, X. Hierarchical ZnO@MnO ${ }_{2} @ P P y$ ternary core-shell nanorod arrays: An efficient integration of active materials for energy storage. RSC Adv. 2015, 5, 39864-39869. [CrossRef]

34. Sugunan, A.; Warad, H.C.; Boman, M.; Dutta, J. Zinc oxide nanowires in chemical bath on seeded substrates: Role of hexamine. J. Sol-Gel Sci. Technol. 2006, 39, 49-56. [CrossRef]

35. Strano, V.; Urso, R.G.; Scuderi, M.; Iwu, K.O.; Simone, F.; Ciliberto, E.; Spinella, C.; Mirabella, S. Double role of HMTA in ZnO nanorods grown by chemical bath deposition. J. Phys. Chem. C 2014, 118, 28189-28195. [CrossRef]

36. Greene, L.E.; Law, M.; Tan, D.H.; Montano, M.; Goldberger, J.; Somorjai, G.; Yang, P. General route to vertical $\mathrm{ZnO}$ nanowire arrays using textured $\mathrm{ZnO}$ seeds. Nano Lett. 2005, 5, 1231-1236. [CrossRef]

37. Arulepp, M.; Permann, L.; Leis, J.; Perkson, A.; Rumma, K.; Jänes, A.; Lust, E. Influence of the solvent properties on the characteristics of a double layer capacitor. J. Power Sources 2004, 33, 320-328. [CrossRef]

38. Allagui, A.; Freeborn, T.J.; Elwakil, A.S.; Maundy, B.J. Reevaluation of performance of electric double-layer capacitors from constant-current charge/discharge and cyclic voltammetry. Sci. Rep. 2016, 6, 38568. [CrossRef]

39. Xiang, C.; Li, M.; Zhi, M.; Manivannan, A.; Wu, N. A reduced graphene oxide $/ \mathrm{Co}_{3} \mathrm{O}_{4}$ composite for supercapacitor electrode. J. Power Sources 2013, 226, 65-70. [CrossRef]

40. Theerthagiri, J.; Karuppasamy, K.; Durai, G.; Rana, A.U.H.S.; Arunachalam, P.; Sangeetha, K.; Kuppusami, P.; Kim, H.-S. Recent advances in metal chalcogenides (MX.; X S, Se) nanostructures for electrochemical supercapacitor applications: A brief review. Nanomaterials 2018, 8, 256. [CrossRef]

41. Subramanian, V.; Zhu, H.; Vajtai, R.; Ajayan, P.M.; Wei, B. Hydrothermal synthesis and pseudocapacitance properties of $\mathrm{MnO}_{2}$ nanostructures. J. Phys. Chem. B 2005, 109, 20207-20214. [CrossRef] [PubMed]

42. Zhong, C.; Deng, Y.; Hu, W.; Sun, D.; Han, X.; Qiao, J.; Zhang, J. Electrolytes for Electrochemical Supercapacitors; CRC Press, Taylor \& Francis Group: New York, NY, USA, 2016.

(C) 2020 by the authors. Licensee MDPI, Basel, Switzerland. This article is an open access article distributed under the terms and conditions of the Creative Commons Attribution (CC BY) license (http://creativecommons.org/licenses/by/4.0/). 